\title{
The Effects of Daylight Saving Time Changes on Stock Market Volatility
}

\author{
Hakan Berument \\ Department of Economics \\ Bilkent University \\ 06800 Ankara Turkey \\ Phone: +90 3122902342 \\ Fax: +90 3122665140 \\ E-mail: berument@bilkent.edu.tr \\ URL: http://www.bilkent.edu.tr/ berument
}

\author{
Nukhet Dogan \\ Department of Econometrics \\ Gazi University \\ 06420 Ankara Turkey \\ Phone: +90 312212 6853/1228 \\ Fax: +90 3122132036 \\ E-mail: nukhed@gazi.edu.tr \\ URL: http://nukhetdog.googlepages.com \\ and \\ Bahar Onar \\ Department of Economics \\ Bilkent University \\ 06800 Ankara Turkey \\ Phone: +90 3122901584 \\ Fax: +90 3122665140 \\ E-mail: onar@bilkent.edu.tr
}




\title{
The Effects of Daylight Saving Time Changes on Stock Market Volatility
}

\begin{abstract}
This study investigates the presence of the Daylight Saving Time change effects on stock returns and on stock volatility using an EGARCH specification to model the conditional variance. The evidence gathered from the major US stock markets for the period between 1967 and 2007 does support the existence of the Daylight Saving Time effect neither in stock returns and nor in volatility. Thus, this paper supports the argument made by Pinegar (2002) on the non-existence of the daylight saving effects on the stock market returns.
\end{abstract}

Jel Codes: G10, G12 and C22.

Key Words: Daylight Saving Time Change, Stock Market Volatility and EGARCH Models. 


\section{Introduction}

Regularities in stock market returns as well as volatilities are important for investors and portfolio managers. If certain patterns in stock returns and volatility can be identified, these patterns might benefit investors in valuation, portfolio optimization, option pricing and risk management. This paper examines whether stock market returns and stock market volatility move with daylight saving time changes when the clocks are adjusted twice a year to benefit from the daylight - daylight savings start with the forward adjustment of clocks by one hour in spring, and end in fall with the backward adjustment of clocks.

Calendar anomalies are well-documented subjects in finance literature. Various studies have found that asset returns are different on different days of the week, on different months of the year, turn of the month and before holidays. In an article, Kamstra, Kramer and Levi (2000) find evidence of a new financial market anomaly Daylight Saving Time (DST) changes. Most of the work for this issue is on the stock market returns, yet this paper assesses any regularity in stock market volatility for the DST changes.

DST changes might have adverse effects on the well-being of individuals. The studies conducted on the health effects of DST changes focuse on its adverse effects on the daily biological rhythms, i.e. circadian rhythm, and on the sleeping patterns of the individuals. Monk and Folkard (1976) find that transitions into and out of DST causes significant sleep disruptions during the physiological adjustment phase. According to Lahti et al. (2006, 2008), DST changes lead to decreases in sleep duration and in sleep efficiency, and these adverse effects on the quality of sleep affect mood and alertness of the individuals in a negative way.

Perry and Dawson (1988) suggest that what is experienced in DST change weeks is quite similar to the effects of jet lag; a decrease in mental and in physical performance. As they call it, DST changes are the "jet lag in your bedroom". Coleman (1986) lists the symptoms of jet lag as fatigue, disorientation, decreased concentration and performance, insomnia and excessive sleepiness. He suggests that these symptoms are associated with the disparity between the actual time and individual's biological clock, and are not observed when traveling in the same time zone. Foster and Kreitzman (2004) point out to a warning in British Airways' advice to travelers; “...effects of jet lag might be quite severe, with decision making ability downgraded 
by up to 50 percent, communication skills by 30 percent, memory by 20 percent and attention by 75 percent."

Some researchers, in fact, find an increase in the number of traffic accidents during the first weeks of the DST changes. Varughese and Allen (2001) find a significant increase in traffic accidents in the US following the DST changes in spring and also in fall. They argue that this is due to the physiological adjustments and to the behavioral responses to "forced changes in the circadian rhythms", as well as to the sleep loss in the spring time. Coren (1996a, 1996b) finds a significant increase on traffic accidents in Canada and on other vehicle operation in US after spring time adjustments, but nonsignificant decreases in fall.

Kamstra et al. (2000) elaborate on the DST change effects on investor behavior. They find that the average returns for DST weekends (fall and spring combined) are significantly lower than that of the regular weekends in the US, Canada and UK stock markets. ${ }^{1}$ A possible cause of this effect, they claim, is the anxiety caused by the disruption in sleeping patterns. The effect is lower average returns, whether it is the start of the daylight saving period in spring when sleeping hours decrease, or the end of the daylight savings period in fall when sleeping hours increase. In either direction the anxiety caused leads traders to be risk averse, to choose safer investments, and decrease the returns. Pinegar (2002) replicates Kamstra et al. (2000) study for the US stock market. The DST effect is present and significant only when fall and spring DST changes are considered together; yet, when treated separately only the mean difference in fall changes remains significant; and this significance vanishes if corrections for heteroskedasticity are made. Kamstra et al. (2002) maintain their claims for the existence of DST effect by showing that the distribution of returns on DST weekends shift entirely to the left, indicating higher number of negative observations and lack of positive ones.

Lamb et al. (2004) find results similar to Pinegar (2002) that only fall DST are significant and this significance decreases when two outliers in October observations are dropped. The remaining effect, they claim, might be due to October effect rather than a fall DST effect. Worthington (2003), and Boido and Fasano (2005) test the presence of the DST effect in Australian and in Italian stock markets respectively. Both studies treat fall and spring DST changes separately. And on contrary to the

\footnotetext{
${ }^{1}$ While lower returns are observed for the daylight saving weekends, the difference is not statistically significant for Germany. This result might be due to the small number of observations available for Germany.
} 
existing work, they expect opposing effects from the spring and fall DST changes. ${ }^{2}$ They cannot find evidence of the DST effect on returns. ${ }^{3}$

The work cited above look at the possible effect of DST changes on stock market returns. However, stock market volatility and its regularity are also of interest for investors (Franses and Paap, 2000 and Berument and Kiymaz, 2001). Kamstra et al. (2000) also claim that there is an effect of the DST on perceived risk. They remark that "if sleep desynchronosis causes market participants to suffer greater anxiety about a given situation, ceteris paribus, they may prefer safer investments and shun risk in trades during the trading day following such a disturbance in their sleep patterns". In this study we look at the effect of the DST changes on perceived risk measured by conditional volatility, which is modeled using an Exponential Generalized Autoregressive Conditional Heteroscedastic (EGARCH) specification.

The rest of the paper is organized as follows. Section 2 describes the data and the methodology used, Section 3 gives the empirical evidence for various specifications and Section 4 concludes.

\section{Data and Methodology}

This study investigates the possible DST change effects on stock returns and volatility using equally and value weighted daily indexes of NYSE, S\&P500, NASDAQ and AMEX obtained from the Center for Research in Security Prices (CRSP).

The DST had been in effect in US during the two World Wars as a war time regulation with the aim of conserving energy and was abolished immediately after the wars ended. While there were no existing federal laws on daylight saving adjustments, some of the states choose to continue with the daylight savings after the wars, but the inconsistency in the way time adjustments were made created problems. In 1966 Federal Government passed The Uniform Time Act, and regulated the start of the daylight saving period as the last Sunday of April and end of the daylight saving period as the last Sunday of October for any state that wants to observe daylight

\footnotetext{
${ }^{2}$ From the initial survey of the index under consideration, Worthington (2003) claims spring daylight changes have an adverse effect on returns (due to the decrease in sleeping hours), and Boido and Fasano (2005) claim spring daylight changes have favorable effect on returns (due to the increase in the daylight and the resulting good mood).

${ }^{3}$ Boido and Fasano (2005) use a different statistical approach. They construct two average return series including the mean returns for the 15 days preceding and the 15 days following the fall and spring time changes. They conclude that the mean return of daylight saving days does not correspond to an extrema in this series, therefore there is no evidence of the daylight saving effect.
} 
saving time. Beginning in 1967, daylight savings started to be observed in a regular basis within the US with the exception of a few states. In 1974, due to the first OPEC oil crisis, adjustment back to the standard time did not take place. With an amendment to federal law in 1986, taking effect in 1987, daylight saving time was extended and the starting date established as the first Sunday of April with no change to the ending date. As an energy conservation measure, with the 2005 US Energy Policy Act, daylight saving period is extended for an additional month; beginning in 2007 the start of daylight saving period is established as the second Sunday of March, and the end as the first Sunday of November (Douma, 2008). Since Congress concludes to step in to end the confusion and to establish one pattern across US in 1967, our data includes observations from January 03, 1967 to June 29, 2007 for NYSE, S\&P500 and AMEX series and include observations from December 15, 1972 to June 29, 2007 for NASDAQ series due to the data availability.

In order to capture the perceived risk we use an $\mathrm{ARCH}$ type of conditional variance model where conditional variance is a function of the lagged values of the return innovations (and lagged values of the conditional variances). ${ }^{4} \mathrm{ARCH}$ models of volatility are powerful in explaining the observed volatility clustering in financial time series. There are various classes of ARCH models, and here we consider Nelson's (1991) Exponential Generalized ARCH model. ${ }^{5}$ EGARCH specification models the logarithm of conditional variance rather than the series itself so that the implied volatility is always positive, and also by the introduction of weighted innovations into the variance specification it allows positive and negative shocks to affect volatility differently (see Hamilton, 1994, for details)

The time varying variance modeled by using an $\operatorname{EGARCH}(p, q)$ process can be written as:

$R_{t}=\mu_{t}+\varepsilon_{t}$

$\log \left(h_{t}^{2}\right)=V_{c}+\sum_{j=1}^{q} V_{j a} g\left(z_{t-j}\right)+\sum_{j=1}^{p} V_{j b} \log \left(h_{t-j}^{2}\right)$

$g\left(z_{t}\right)=\left|z_{t}\right|-E\left|z_{t}\right|+\chi z_{t}$

\footnotetext{
${ }^{4}$ See Berument et al. (2005) for comparison of volatility measures.

${ }^{5}$ Tsay (2005) and Engle et al. (2008) provide excellent review of ARCH models. Pagan and Schwert (1990), Engle and $\mathrm{Ng}$ (1993) compare various ARCH specifications, and evaluate the performance of these existing models in capturing the observed behavior in the stock returns.
} 
where, $R_{t}$ is the stock market return, $\mu_{t}$ is the expected return, $\varepsilon_{t}$ is the residual, $h_{t}^{2}$ is the conditional variance of the error term $\varepsilon_{t}$, and $z_{t}$ is the standardized residual $z_{t}=\varepsilon_{t} / h_{t}$ at time $t$. Here we assume that $z_{t}$ has a General Error Distribution $(G E D(0,1)) .{ }^{6} V_{c}, V_{j a}, V_{j b}$ and $\chi$ are the parameters to be estimated.

The introduction of the weighted innovations $g\left(z_{t}\right)$ in the conditional variance specification enables the model to respond differently to positive and negative return shocks. Here, $\chi$ is the coefficient for the sign effect (or the leverage effect), and $V_{j a}$ is the coefficient for the size effect. If $\chi=0$ then only the size of the shocks matter, the change in conditional volatility to negative and positive shocks is symmetric. $\chi<0$ coupled with $V_{j a}>0$ implies an asymmetric effect of negative and positive shocks on volatility. Black (1976) and Christie (1982) provide the earliest empirical studies on the asymmetric effects of negative and positive shocks on volatility, or the so-called leverage effect; and they show that volatility increases with "bad news", and decreases with "good news". Of the later studies on the leverage effect Glosten, Jagannathan and Runkle (1993) find $\chi<-1$, a result that is in line with Black (1976) and Christie (1982); while Nelson (1991), Engle and $\mathrm{Ng}$ (1993) find $-1<\chi<0$, which implies both negative and positive shocks increase conditional variance, with negative ones having larger effects than the positive ones.

In our first model, we assume that expected return is a function of lagged values of returns and also that the expected returns are different on Mondays and DST changes. Modeling returns using daily dummies and lagged returns are common (see Cross, 1973; French, 1980 and Gibbons and Hess, 1981) First we consider the DST effect both in return and volatility equations.

$$
\begin{aligned}
& R_{t}=\alpha_{0}+\alpha_{M} M_{t}+\alpha_{D} D_{t}+\alpha_{i} \sum_{i=1}^{n} R_{t-i}+\varepsilon_{t} \\
& \log \left(h_{t}^{2}\right)=V_{c}+V_{M} M_{t}+V_{D} D_{t}+\sum_{j=1}^{q} V_{j a}\left[\left|\frac{\varepsilon_{t-j}}{h_{t-j}}\right|-E\left(\left|\frac{\varepsilon_{t-j}}{h_{t-j}}\right|\right)+\chi \frac{\varepsilon_{t-j}}{h_{t-j}}\right]+\sum_{j=1}^{p} V_{j b} \log \left(h_{t-j}^{2}\right)
\end{aligned}
$$

\footnotetext{
${ }^{6}$ For a generalized error distribution (GED) for variable $z_{t}, E\left(\left|z_{t}\right|\right)=\lambda 2^{1 / v} \Gamma(2 / v) / \Gamma(1 / v)$ where $\Gamma(\cdot)$ is the gamma function and $\lambda \equiv\left[2^{-2 / v} \Gamma(1 / v) / \Gamma(3 / v)\right]^{1 / 2}$. Here, $v$ is a positive shape parameter governing the thickness of the tails of the distribution; for $v=2$ GED has the same form as the normal distribution, for $v>2$ density has thicker tails and for $v<2$ density has thinner tails than the normal distribution. Consequently GED includes various distributions, normal distribution being a special case.
} 
where $M_{t}$ and $D_{t}$ are the Monday and the DST change dummies (for fall and spring combined) respectively. In order to see the difference between Mondays following DST changes and regular Mondays we include both dummy variables. We are modeling conditional variance as an EGARCH process with the inclusion of some exogenous variables to the specification, namely Monday and DST dummies. In the literature also there is a set of studies that suggests the presence of systematic variation in stock market volatility. Some examples of such studies are French and Roll (1986), Foster and Viswanathan (1990 and 1993), Mookerjee and Yu (1999), Franses and Paap (2000), Berument and Kiymaz (2001), Kiymaz and Berument (2003), and Savva, Osborn and Gill (2006).

We used final prediction error criteria (FPEC) to determine the optimal autoregressive order $n$. As Casimano and Jansen (1988) argue, eliminating autocorrelation in the residual terms is crucial; since, having autocorrelated errors would lead to misleading test results for conditional variance specification, predicting heteroskedasticity even in the case of homoskedasticity.

In our second model, we allow stock market volatility to affect the return but we could only include DST change and Monday effects in the volatility equation. One could suggest including the DST and Monday dummies in the return equation as well but introducing intercept dummies both in mean and variance equations, the twoequation model could not be jointly estimated due to the perfect multicollinearity. The source of the perfect multicollinearity is the presence of a return-volatility relationship in the mean equation. This presence will lead the DST and Monday dummies to be accounted for twice in the mean equation; one through the intercept dummies in the mean itself and the other through the ones in the variance equation. Therefore in this second model we do not include intercept DST and Monday dummies to the return equation.

$$
\begin{aligned}
& R_{t}=\alpha_{0}+\alpha_{i} \sum_{i=1}^{n} R_{t-i}+\lambda h_{t}^{2}+\varepsilon_{t} \\
& \log \left(h_{t}^{2}\right)=V_{c}+V_{M} M_{t}+V_{D} D_{t}+\sum_{j=1}^{q} V_{j a}\left[\left|\frac{\varepsilon_{t-j}}{h_{t-j}}\right|-E\left(\left|\frac{\varepsilon_{t-j}}{h_{t-j}}\right|\right)+\chi \frac{\varepsilon_{t-j}}{h_{t-j}}\right]+\sum_{j=1}^{p} V_{j b} \log \left(h_{t-j}^{2}\right)
\end{aligned}
$$

where conditional variance is used as a proxy for the return volatility. Since asset returns are positively related to their volatility in case of risk aversion, we would expect the risk premium parameter $\lambda$ to be positive. While our first model given by equations (2) and (3) tests for the direct effect of Mondays and DST changes on stock 
returns and volatility; this second model tests for their indirect effect on returns, Mondays and DST changes affecting stock volatility and hence stock returns through the risk premium. We use the quasi-maximum likelihood estimation (QMLE) method for estimation purposes. ${ }^{7}$

\section{Empirical Evidence}

Tables 1 and 2 report our estimates for the equally weighted and value weighted daily returns of NYSE, S\&P500, NASDAQ and AMEX. Panel A of Table 1 reports the estimates of our return equation as specified in equation (2) and Panel B of Table 1 reports the estimates of our (conditional) variance as specified in equation (3).

For the return equation, the estimated Monday dummy coefficients are always negative and statistically significant at the $1 \%$ level for all indexes; Monday effect is present, and Monday returns are consistently lower and negative for all of the series under consideration. This result is in line with Cross (1973), and Gibbons and Hess (1981) and French (1980) among others. Estimated coefficients for the DST dummies are mostly negative except for the equally weighted S\&P500 index, but they are not statistically significant. Pinegar (2002) and Lamb et al. (2004) studies for the USA stock market give similar results that there is no statistically significant DST effect on returns.

Panel B reports the estimates of the conditional volatility specification. Monday dummy coefficients in the volatility specification suggest the presence of the day of the week effect in return volatility. These coefficients are all positive and significant at the $1 \%$ level. This finding is parallel to French and Roll (1986). They argue that variances for the days following a holiday are larger than those for the other days. The Monday effect is present both in return and in return volatility; Mondays having low returns and high volatility. As Campbell and Hentschel (1992) suggest, an increase in stock market volatility raises the required rate of return on common stocks and hence lowers stock returns.

The estimated coefficients of DST dummies in the volatility specification are mostly negative with the exception of equally weighted and value weighted

\footnotetext{
${ }^{7}$ As noted by Pagan (1984) when constructed variables are used in regressions usual estimation techniques leads to inefficiencies and invalid inferences. Pagan and Ulah (1988) suggest joint estimation using maximum likelihood estimation (MLE) method to overcome these problems. Bollerslev and Wooldridge (1992) points out MLE is not robust to non-normality in error distribution, and suggest the use of quasi-maximum likelihood estimation (QMLE) method instead, where the assumption of normality can be relaxed. QMLE is generally consistent, has limited distribution and provide asymptotic standard errors that are valid even under non-normality of the errors.
} 
NASDAQ indexes, but not statistically significant at the $10 \%$ level. Thus, DST effect could not be found in stock market volatility as couldn't be found in stock market returns.

For the conditional variance specifications, the characteristic roots of the polynomials are all inside the unit circle, thus, the conditional variance specification is not explosive (see Nelson, 1991).

Our results on the time varying conditional variance show strong evidence of volatility clustering; the estimated coefficients for $\left[\left|\frac{\varepsilon_{t-1}}{h_{t-1}}\right|-E\left(\left|\frac{\varepsilon_{t-1}}{h_{t-1}}\right|\right)+\chi \frac{\varepsilon_{t-1}}{h_{t-1}}\right]$ are statistically significant. Furthermore, these coefficients are positive implying that independent of the sign of shocks, large shocks lead to larger changes and small shocks lead to smaller changes in volatility.

Estimated negative and statistically significant sign effect coefficients $(\chi)$ confirm the asymmetric response of volatility to negative and positive shocks. The negative shocks increase volatility more than equally sized positive shocks. These results are in line with the findings of Nelson (1991), Engle and $\mathrm{Ng}$ (1993), Cheung and $\mathrm{Ng}$ (1992), and Kim and Kon (1994).

The first part of Panel $\mathrm{C}$ of Table 1 reports $p$-values for the Ljung-Box statistics for various lag-lengths to test for the serial correlation in the standardized residuals. The overall results suggest that the null hypothesis of no autocorrelation in the first $m$ lags of standardized residuals cannot be rejected so no serial correlation is left in the return series, with the exception of equally weighted NASDAQ and AMEX indexes where there is some indication of serial correlation at lags 20 and 60; and 5 and 60, respectively.

We also report the Ljung-Box tests for the squared standardized residuals to examine the adequacy of the fitted conditional variance model. $p$-values for these statistics for the various lags are given also in the second part of Panel $\mathrm{C}$ of Table 1. Given the results for the Ljung-Box tests, we cannot reject the null hypothesis that first $m$ lags of the squared standardized residuals are uncorrelated, and conclude that the standardized residuals have constant variances.

Our second specification allows a possible interaction between stock market return and volatility. In this case, we could only introduce the DST and Monday dummies to volatility specification (as discussed in the previous section). Panels A and $\mathrm{B}$ of Table 2 reports the estimation results for this second specification, as given 
in equations (4) and (5). Coefficients of the conditional variance in the return equation are positive for all and statistically significant for the equally weighted series with the exception of NASDAQ however, generally insignificant for the value weighted series with the exception of S\&P500 series. The relation between expected returns and current volatilities is positive, indicating that compensation in terms of higher returns is required for taking higher risk.

The estimates on conditional variance are robust to our return equation specification. The estimated EGARCH coefficients show that results on (i) negative and statistically significant Monday effect; (ii) statistically insignificant DST effect on stock market volatility are in line with the estimates reported in Table 1. Moreover, as reported before the presence of volatility clustering, asymmetric response to negative and positive shocks are still robust. ${ }^{8}$

Panel $\mathrm{C}$ of Table 2 reports the $p$-values for the the Ljung-Box statistics for the standardized residuals and the squared standardized residuals to test the presence of the autocorrelation. Overall, we cannot reject the null hypothesis that the residuals are not autocorrelated for any of the indexes except equally weighted index of AMEX for all lags, equally weighted NYSE, NASDAQ and value weighted NASDAQ, AMEX for 60 lags at 5\% level. Results for the Ljung Box test for the squared standardized residuals suggest that no ARCH errors are left overall, but for one. For the equallyweighted NASDAQ series we have at least one autocorrelation coefficient in the fifthorder that is different than zero, and hence there are ARCH errors of the autoregressive type.

\section{Conclusions}

Based on a recent paper by Kamstra et al. (2000) on the Daylight Saving Time (DST) effects on stock returns, we investigate the presence of this new possible calendar anomaly in stock returns and also in stock volatility using an EGARCH specification to model conditional variance. The evidence obtained from NYSE,

\footnotetext{
${ }^{8}$ When we repeated our analysis for fall and spring daylight saving time changes separately, we obtained similar results. Spring and fall daylight saving time changes have negative effects on returns but these effects are not statistically significant. Volatility in spring daylight saving Mondays is higher, and it is lower in fall daylight saving Mondays; but again results are statistically insignificant with the exception of NYSE equally weighted and AMEX value weighted indexes for our first specification, and AMEX value weighted index for the second specification. These results are not reported, but can be obtained from the authors upon request.
} 
S\&P500 and AMEX equally weighted and value weighted indexes for the period January 03, 1967 to June 29, 2007, and NASDAQ value weighted and equally weighted indexes for the period December 15, 1972 to June 29, 2007 support the existence of DST effect neither on returns nor on volatility. This result is in line with the results of Pinegar (2002) and Lamb et al. (2004) in finding no DST effect on returns in the US stock markets. While there is no evidence of the DST effect, the well-known Monday effect is present in the data; Mondays are the days with low expected returns and high volatility. The asymmetric effect of negative and positive shocks on volatility is apparent in the data, with negative shocks increasing volatility more than equally sized positive shocks. 
Table 1 - Daylight Saving Time Effect in Return and Volatility Equations

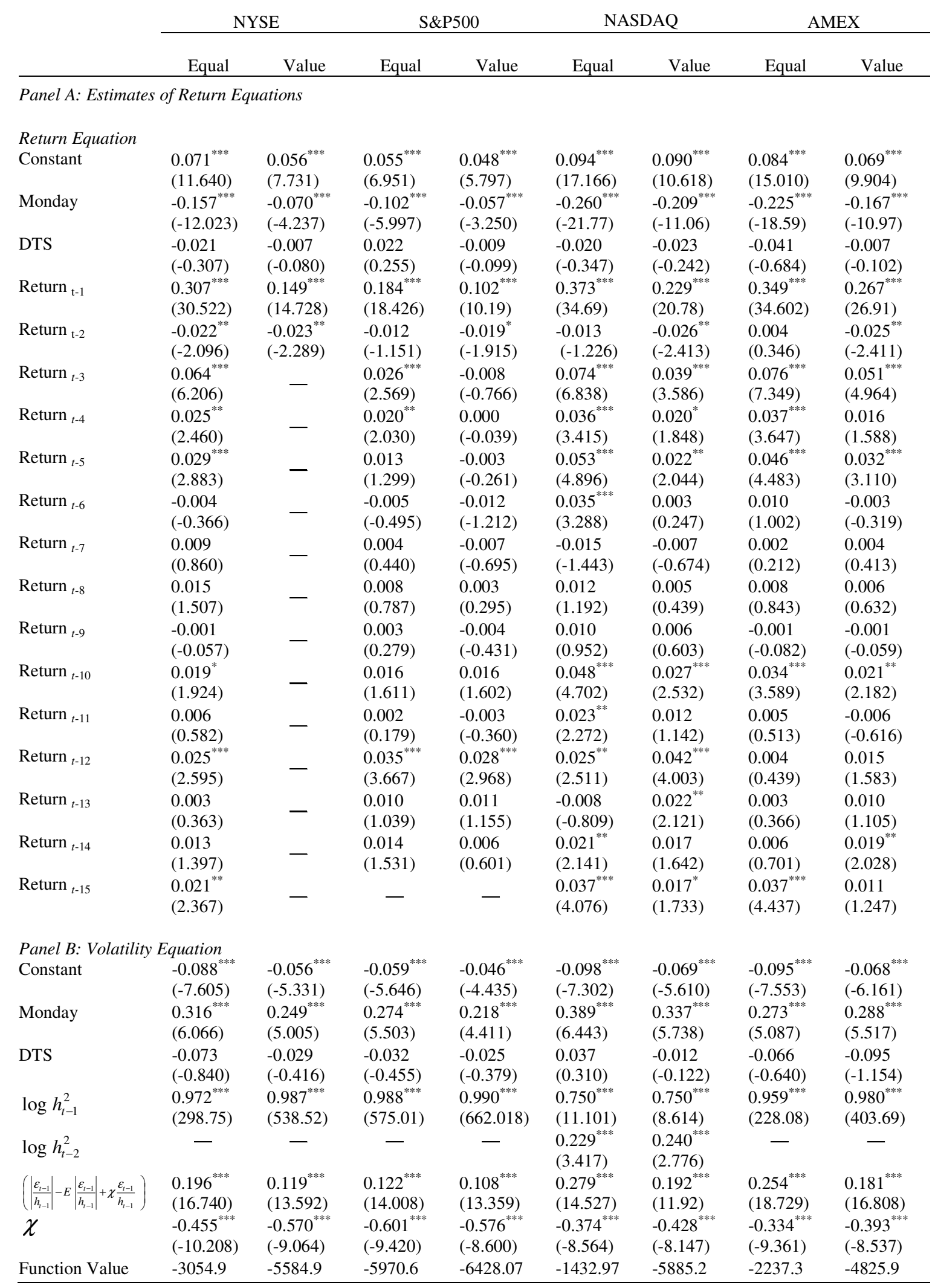


TABLE 1 - (continued)

\begin{tabular}{|c|c|c|c|c|c|c|c|c|}
\hline & \multicolumn{2}{|c|}{ NYSE } & \multicolumn{2}{|c|}{ S\&P500 } & \multicolumn{2}{|c|}{ NASDAQ } & \multicolumn{2}{|c|}{ AMEX } \\
\hline & Equal & Value & Equal & Value & Equal & Value & Equal & Value \\
\hline \multicolumn{9}{|c|}{ Panel C: Robustness Statistics } \\
\hline $\operatorname{Lag}(s)$ & \multicolumn{8}{|c|}{ Ljung-Box Q-Statistics } \\
\hline 5 & {$[0.108]$} & {$[0.543]$} & {$[0.700]$} & [0.763] & [0.177] & [0.742] & {$[0.042]^{* *}$} & {$[0.810]$} \\
\hline 10 & {$[0.430]$} & {$[0.690]$} & [0.936] & [0.971] & [0.131] & [0.934] & {$[0.201]$} & [0.985] \\
\hline 20 & {$[0.615]$} & {$[0.750]$} & [0.994] & [0.992] & {$[0.092]^{*}$} & {$[0.944]$} & {$[0.201]$} & [0.991] \\
\hline 60 & {$[0.107]$} & {$[0.396]$} & {$[0.574]$} & {$[0.756]$} & {$[0.004]^{* * *}$} & {$[0.226]$} & {$[0.001]^{* * *}$} & {$[0.403]$} \\
\hline $\operatorname{Lag}(s)$ & \multicolumn{8}{|c|}{ Ljung-Box Q-Statistics for the squared normalized residuals } \\
\hline 5 & {$[0.930]$} & {$[0.927]$} & {$[0.973]$} & {$[0.811]$} & {$[0.236]$} & {$[0.648]$} & {$[0.924]$} & [0.324] \\
\hline 10 & {$[0.777]$} & {$[0.988]$} & [0.995] & [0.949] & [0.269] & {$[0.674]$} & [0.899] & {$[0.366]$} \\
\hline 20 & {$[0.878]$} & [0.998] & [0.999] & {$[0.988]$} & {$[0.324]$} & [0.699] & [0.959] & {$[0.447]$} \\
\hline 60 & {$[0.563]$} & {$[0.460]$} & {$[0.201]$} & {$[0.307]$} & {$[0.121]$} & {$[0.268]$} & {$[0.967]$} & {$[0.869]$} \\
\hline
\end{tabular}


Table 2 - Daylight Saving Time Effect in Volatility Equation

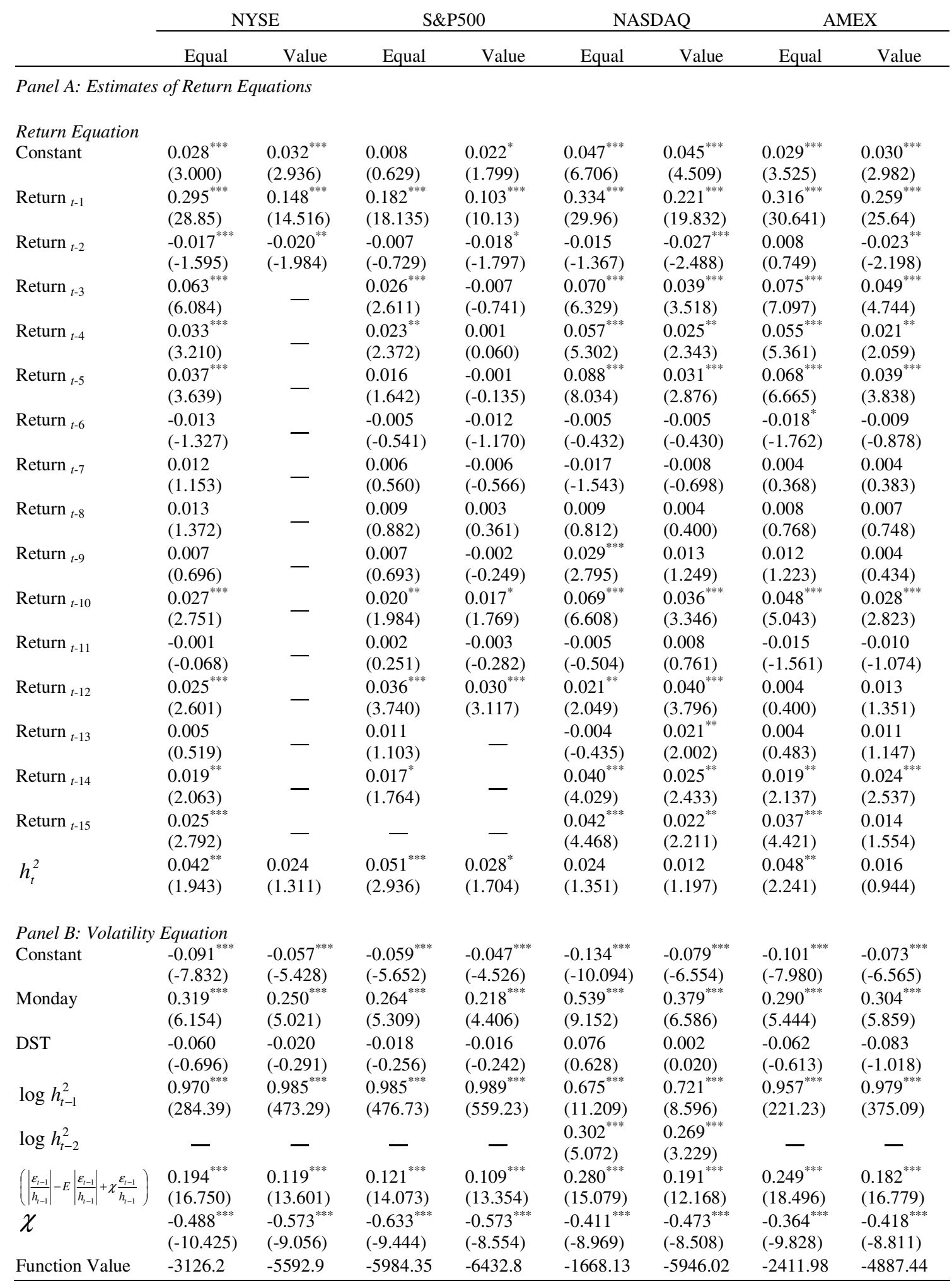


TABLE 2 - (continued)

\begin{tabular}{|c|c|c|c|c|c|c|c|c|}
\hline & \multicolumn{2}{|c|}{ NYSE } & \multicolumn{2}{|c|}{ S\&P500 } & \multicolumn{2}{|c|}{ NASDAQ } & \multicolumn{2}{|c|}{ AMEX } \\
\hline & Equal & Value & Equal & Value & Equal & Value & Equal & Value \\
\hline \multicolumn{9}{|c|}{ Panel C: Robustness Statistics } \\
\hline $\operatorname{Lag}(\mathrm{s})$ & \multicolumn{8}{|c|}{ Ljung-Box Q-Statistics } \\
\hline 5 & {$[0.048]$} & {$[0.555]$} & {$[0.665]$} & {$[0.771]$} & [0.382] & [0.677] & {$[0.004]^{\text {**** }}$} & {$[0.738]$} \\
\hline 10 & {$[0.263]$} & {$[0.695]$} & [0.928] & [0.977] & [0.719] & [0.910] & {$[0.051]^{* *}$} & {$[0.977]$} \\
\hline 20 & {$[0.245]$} & [0.716] & [0.992] & [0.994] & {$[0.028]^{* *}$} & {$[0.658]$} & {$[0.002]^{\text {**** }}$} & {$[0.955]$} \\
\hline 60 & {$[0.004]^{\text {*** }}$} & {$[0.370]$} & {$[0.548]$} & {$[0.770]$} & {$[0.000]^{* * *}$} & {$[0.000]^{* * * *}$} & {$[0.000]^{\text {**** }}$} & {$[0.091]^{*}$} \\
\hline $\operatorname{Lag}(\mathrm{s})$ & \multicolumn{8}{|c|}{ Ljung-Box Q-Statistics for the squared normalized residuals } \\
\hline 5 & {$[0.966]$} & {$[0.933]$} & {$[0.980]$} & {$[0.819]$} & {$[0.055]^{*}$} & {$[0.478]$} & [0.943] & [0.397] \\
\hline 10 & {$[0.797]$} & [0.989] & [0.996] & {$[0.952]$} & {$[0.163]$} & {$[0.522]$} & [0.862] & {$[0.419]$} \\
\hline 20 & {$[0.893]$} & [0.999] & [0.999] & {$[0.989]$} & {$[0.220]$} & {$[0.710]$} & {$[0.962]$} & {$[0.549]$} \\
\hline 60 & {$[0.544]$} & {$[0.420]$} & {$[0.188]$} & {$[0.266]$} & {$[0.176]$} & {$[0.558]$} & [0.969] & {$[0.827]$} \\
\hline
\end{tabular}

$t$-statistics are reported in parentheses and $p$-values in brackets.

* Indicates statistical significance at $10 \%$ level.

** Indicates statistical significance at 5\% level.

${ }^{* * *}$ Indicates statistical significance at $1 \%$ level. 


\section{References}

Berument, H., and H. Kiymaz, 2001, "The Day of the Week Effect on Stock Market Volatility," Journal of Economics and Finance, 25(2), 181-193.

Berument H., Z. Kilinc and U. Ozlale, 2005, "The Missing Link Between Inflation Uncertainty and Interest Rates", Scottish Journal of Political Economy, 52(2), 222241.

Black, F., 1976, "Studies of Stock Market Volatility Changes," 1976 Proceedings of the American Statistical Association, Business and Economic Statistics Section, 177181.

Boido, C., and A. Fasano, 2005, "Calendar Anomalies: Daylight Savings Effects," Presented in 2005 FMA European Conference.

Bollerslev, T., and J. M. Wooldridge, 1992, "Quasi-Maximum Likelihood Estimation and Inference in Dynamic Models with Time-Varying Covariances," Econometric Reviews, 11(2), 143-172.

Campbell, J. Y., and L. Hentschel, 1992, "No News is Good News: An Asymmetric Model of Changing Volatility in Stock Returns," Journal of Financial Economics, 31(3), 281-318.

Casimano, T. F., and D. W. Jansen, 1988, "Estimates of the Variance of U.S. Inflation Based upon ARCH Model," Journal of Money, Credit and Banking, 20(3), 409-421.

Cheung, Y., and L. K. Ng, 1992, "Stock Price Dynamics and Firm Size: An Empirical Investigation," Journal of Finance, 47(5), 1985-1997.

Christie, A. A., 1982, "The Stochastic Behavior of Common Stock Variances: Value, Leverage and Interest Rate Effects," Journal of Financial Economics, 10(4), 407-432.

Coleman, R. M., 1986, Wide Awake at 3:00 A.M. by Choice or by Chance? , W. H. Freeman and Company: New York.

Coren, S.,1996a, "Daylight Savings Time and Traffic Accidents," New England Journal of Medicine, 334, 924.-925.

Coren, S., 1996b, "Accidental Death and the Shift to Daylight Savings Time," Perceptual and Motor Skills, 83, 921-922.

Cross, F., 1973, "The Behavior of Stock Prices on Friday and Monday," Financial Analysts Journal, 29(6), 67-69.

Douma, M. Curator, 2008, "Early Adoption and the US Law" Daylight Saving Time, http://www.webexhibits.org/daylightsaving/e.html, (accessed March 12, 2008).

Engle, R. F., and V. K. Ng, 1993, "Measuring and Testing the Impact of News on Volatility," The Journal of Finance, 48(5), 1749-1778.

Engle R. F., S. M. Focardi and F. J. Fabozzi, 2008, ARCH/GACH Models in Applied Financial Econometrics, chapter in The Handbook Series in Finance by Frank J. Fabozzi, John Wiley\&Sons.

Foster, D., and S. Viswanathan, 1990, "A Theory of Interday Variations in Volumes, Variance, and Trading Costs in Securities Markets, Review of Financial Studies, 3(4), 593-624. 
Foster, D., and S. Viswanathan, 1993, "Variations in Trading Volume, Return Volatility, and Trading Costs: Evidence on Recent Price Formation Models,"Journal of Finance, 48(1), 187-211.

Foster, R. G., and L. Kreitzman, 2004, Rhythms of Life: The Biological Clocks that Control the Daily Lives of Every Living Thing, Yale University Press: New Haven and London.

Franses, P. H. and R. Paap, 2000, "Modelling Day of the Week Seasonality in the S\&P 500 Index," Applied Financial Economics, 10(5), 483-488.

French, K. R., 1980, "Stock Returns and the Weekend Effect," Journal of Financial Economics, 8(1), 55-69.

French, K., and R. Roll, 1986, "Stock Return Variances: The Arrival of Information and the Reaction of Traders, Journal of Financial Economics, 17(5), 5-26.

Gibbons, M. R., and P. Hess, 1981, "Day of the Week Effect and Asset Returns," The Journal of Business, 54(4), 579-596.

Glosten, L. R, R. Jagannathan, and D. E. Runkle, 1993, "On the Relation between the Expected Value and the Volatility of the Nominal Excess Returns on Stocks," Journal of Finance, 48(5), 1779-1801.

Hamilton, J. D., 1994, Time Series Analysis, New Jersy: Princeton University Pres.

Kamstra, M. J., L. A. Kramer, and M. D. Levi, 2000, "Losing Sleep at the Market: The Daylight Saving Anomaly," The American Economic Review, 90(4), 1005-1011.

Kamstra, M. J., L. A. Kramer, and M. D. Levi, 2002, "Losing Sleep at the Market: The Daylight Saving Anomaly: Reply," The American Economic Review, 92(4), 1257-1263.

Kim, D. and S. J. Kon, 1994, "Alternative Models for the Conditional Heteroskedasticity of Stock Returns,” The Journal of Business, 67(4), 563-598.

Kiymaz H., and H. Berument, 2003, "The Day of the Week Effect on Stock Market Volatility and Volume: International Evidence," Review of Financial Economics, 12(4), 363-380.

Lahti, T. A., S. Leppämäki, J. Lönnqvist, and T. Partonen , 2008, "Transitions into and out of Daylight Saving Time Compromise Sleep and the Rest-Activity Cycles," BMC Physiology, 8(3).

Lahti, T. A., S. Leppämäki, J. Lönnqvist, and T. Partonen, 2006, "Transition to Daylight Saving Time Reduces Sleep Duration plus Sleep Efficiency of the Deprived Sleep," Neuroscience Letters, 406(3), 174-177.

Lamb, R. P., R. A. Zuber, and J. M. Gandar, 2004, "Don't Lose Sleep on it: Reexamination of the Daylight Savings Anomaly," Applied Financial Economics, 14(6), 443-446.

Monk T. H. , and S. Folkard, 1976, "Adjusting to the Changes to and from Daylight Saving Time,” Nature, 261, 688-689.

Mookerjee, R. and Q. Yu, 1999, “An Empirical Analysis of the Equity Markets in China", Review of Financial Economics, 8(1), 41-60.

Nelson, D. B., 1991, "Conditional Heteroskedasticity in Asset Returns: A New Approach," Econometrica, 59(2), 347-370. 
Pagan, A., 1984, "Econometric Issues in the Analysis of Regressions with Generated Regressors," International Economic Review, 25(1), 221-247.

Pagan, A., and A. Ulah, 1988, "The Econometric Analysis of Models with Risk Terms," Journal of Applied Econometrics, 3(2), 87-105.

Pagan, A., and G. W. Schwert, 1990, "Alternative Models for Conditional Stock Volatility," Journal of Econometrics, 45(1-2), 267-290.

Perry, S, and J. Dawson, 1988, The Secrets Our Body Clocks Reveal, Rawson Associates: New York.

Pinegar, J. M., 2002, "Losing Sleep at the Market: Comment," The American Economic Review, 92(4), 1251-1256.

Savva, C. S., D. R. Osborn, and L. Gill, 2006, "The Day of the Week Effect in Fifteen European Stock Markets," University of Manchester.

Tsay, R. S., 2005, Analysis of Financial Time Series, 2nd ed., John Wiley \& Sons: New Jersey.

Varughese, J. and R. P. Allen , 2001, "Fatal Accidents Following Changes in Daylight Savings Time: the American Experience," Sleep Medicine, 2(1), 31-36.

Worthington, A., 2003, "Losing Sleep at the Market: An Empirical Note on the Daylight Saving Anomaly in Australia," Discussion Papers in Economics, Finance, and International Competitiveness \#146, Queensland University of Technology. 